\title{
CURSO PRÉ-VESTIBULAR UNIVERSIDADE PARA TODOS: CONTRIBUICCÕES PARA O ACESSO DE ESTUDANTES AO ENSINO SUPERIOR E AO MERCADO DE TRABALHO
}

\author{
PRE-VESTIBULAR COURSE UNIVERSIDADE PARA TODOS: CONTRIBUTIONS \\ TO ACCESS TO STUDENTS TO HIGHER EDUCATION AND THE LABOR MARKET
}

\author{
E. C. SOUSA ${ }^{1}$, C. P. NUNES ${ }^{1}$, G. S. SOUSA ${ }^{1}$
}

1 Universidade Estadual do Sudoeste da Bahia, Programa de Pós-Graduação em Educação (PPGED), Vitória da Conquista, Bahia, Brasil - erivancosnsultoria01@gmail.com.

\author{
AR T I C LE IN F O \\ Article history: \\ Received 2018-07-10 \\ Accepted 2018-10-15 \\ Available online 2018-10-31

\section{*Autor correspondente:} \\ E-mail: erivancosultoria01@gmail.com
}

Palavras-chave: Pré-vestibular. Ensino superior. Mercado de trabalho.

Keywords: Pre-university course. Higher education. Labor market.

RESUMO: Este trabalho analisa as contribuições do curso pré-vestibular Universidade Para Todos (UPT) para o acesso de jovens ao Ensino Superior. Explana-se sobre a ausência de perspectivas dos estudantes egressos do Ensino Médio no que tange este nível educacional e o baixo grau de instrução dos pais para orientarem os filhos. Salienta-se a importância do curso de nível superior para o enriquecimento intelectual e possibilitar melhores postos no mercado de trabalho. Segue-se a perspectiva metodológica de revisão bibliográfica sobre o tema evidenciado e a análise de entrevistas realizadas com 25 (vinte e cinco) ex-alunos do curso UPT, em Aracatu, Bahia. Os resultados evidenciam que a maioria dos entrevistados opta por cursos de nível superior relacionados a licenciaturas, justificam as escolhas na distância geográfica da universidade, já que é mais viável realizar um curso mais próximo da residência, devido à condição socioeconômica. O curso foi avaliado como excelente ou bom, visto que auxiliou nos vestibulares realizados. Deve-se ter pontualidade na entrega dos materiais didáticos. É perceptível que o curso UPT, mesmo com problemas estruturais, contribuiu para que estes estudantes conseguissem acesso ao ensino superior e ao mercado de trabalho.

\begin{abstract}
This paper analyzes the contributions of the pre-university course Universidade para Todos (UPT) for the access of young people to Higher Education. It is explained about the lack of perspectives of high school students that came from high school and the low level of education of parents to guide their children. Emphasis is given to the importance of the higher education course for intellectual enrichment and to enable better positions in the labor market. The methodological perspective of bibliographic review on the subject and the analysis of interviews with 25 (twenty-five) former UPT students, in Aracatu, Bahia is used in order to develop this work. The results show that most of the interviewees opt for higher level courses related to undergraduate degrees of teaching, justifying the choices in the geographic distance of the university, since it is more feasible to carry out a course closer to the residence due to the socioeconomic condition. The course was evaluated as excellent or good, since it helped in the vestibular tests. It is highly necessary to have punctuality in the delivery of didactic materials. It is noticeable that the UPT course, even with structural problems, contributed to these students gaining access to higher education and the labor market.
\end{abstract}




\section{Introdução}

O percurso histórico sobre a formação de nível superior no Brasil demonstra que, no início, quando não existiam universidades no país, os filhos de famílias abastadas eram enviados para estudarem na Europa, a exemplo da Universidade de Coimbra, localizada na cidade de Coimbra, capital da Coroa portuguesa. Em 1808, quando a família real portuguesa vem para o Brasil, ocorre a criação das primeiras universidades na Colônia, dano início a oferta de curso superior no território nacional. Nesse contexto é necessário destacar que a oferta era muito reduzida e o acesso era limita a poucos. Do mesmo modo é pertinente registar que, por outro lado, a qualidade de pessoas interessadas em fazer curso superior era, igualmente, pequena. (PAIM, 1982).

Até 1910 o acesso a estas instituições era automático. Deste momento em diante, pelo fato de criar, de forma isolada, instituições para a oferta do Ensino Superior, originou-se a necessidade de criação de exames preparatórios. (PAIM, 1982). Constata-se, a partir de 1911, a institucionalização do acesso a esse nível de ensino por meio de Decretos Federais. Um exemplo deste instrumento legal é o Decreto ํo 8.659, de 5 de abril de 1911, o qual instituiu o Exame de Admissão, ressaltando a necessidade da prova escrita de várias disciplinas, conforme aponta o trecho a seguir:

Esses exames consistiam em prova escrita sobre conhecimentos da língua vernácula e uma prova oral sobre leitura com interpretação do texto, conhecimento geral da língua francesa, de geografia e de história do Brasil, e toda a parte prática da aritmética elementar. (SANTOS, 2011, p. 2).

Posteriormente, em 1925, ocorre o estabelecimento de limite de vagas nas instituições, o que reforça ainda mais o caráter seletivo e também excludente do vestibular. Neste sentido, o ingresso na universidade torna-se mais difícil e os que conseguem realizá-lo são as pessoas das classes dominantes, enquanto os das classes periféricas, pelo baixo nível de estudo, não conseguem, ou pouquíssimos conseguem. É importante destacar também que os sujeitos que são filhos de famílias detentoras de maior capital financeiro, recebem maiores investimentos dos pais para capacitação, o que amplia as distâncias entre grupos sociais, haja vista que:

[...] os alunos "bem nascidos", que receberam da família um senso perspicaz do investimento, assim como os exemplos ou conselhos capazes de amparálo em caso de incerteza, estão em condições de aplicar seus investimentos no bom momento e no lugar certo, ou seja, nos bons ramos de ensino, nos bons estabelecimentos, nas boas seções, etc.; ao contrário, aqueles que são procedentes de famílias mais desprovidas e, em particular, os filhos de imigrantes, muitas vezes entregues completamente a si mesmos, desde o fim dos estudos primários, são obrigados a se submeter às injunções da instituição escolar ou ao acaso para encontrar seu caminho num universo cada vez mais complexo e são, assim, voltados a investir, na hora errada e no lugar errado, um capital cultural, no final de contas, extremamente reduzido. (BOURDIEU; CHAMPAGNE, 2003, p. 223).

Percebe-se, então, que os estudantes de classe social menos favorecida passam por um processo tardio de aprendizado, o qual é voluntário e consciente. Eles têm familiaridade demorada com a produção cultural, difundida na escola. Logo, os outros estudantes, que, desde o berço familiar, 
passaram por um processo precoce e insensível, adquirem familiaridade com a referida produção com mais rapidez e assim tendem a entender com mais facilidade a mesma. Estes filhos das elites, têm uma tendência a apreciarem determinados produtos da cultura (livros, filmes, música) que corroboram com o êxito nos processos seletivos, por exemplo.

Neste contexto, o presente estudo pretende esboçar uma revisão bibliográfica referente a estudantes que pertencem a diferentes realidades socioeconômicas e diferentes percursos escolares, debater sobre os cursos pré-vestibulares populares e comunitários, os quais possibilitam a preparação para o acesso ao nível superior. Além disso, almeja-se discutir sobre o curso pré-vestibular Universidade Para Todos (UPT), programa criado pelo governo do estado da Bahia e de que forma o mesmo foi implantando no município de Aracatu-BA. O curso UPT é uma política pública que prepara estudantes que estão concluindo o ensino médio ou que já concluíram para a inserção na educação terciária, desde que tenham estudado em escolas públicas. Há uma explanação a cerca dos resultados de entrevistas realizadas com ex-alunos do curso UPT. Aborda como o curso tem contribuído para o acesso á Ensino Superior, quais as pretensões de cursos, os apontamentos sobre melhorias na estrutura do curso. Além disso, faz-se uma descrição do contexto socioeconômico dos sujeitos da pesquisa. Diante de variadas respostas, o curso UPT, necessita de melhorias metodológicas no que concerne, por exemplo, as aulas e tem auxiliado os estudantes na realização de processos seletivos vestibulares, despertando o desejo de ingressarem ao nível superior e ao mercado de trabalho.

\section{Fundamentação}

Segundo afirma Zago (2006), em uma pesquisa realizada sobre o acesso ao nível superior, não há nada de "natural", no que se refere chegar ao nível superior, haja vista que muitos estudantes, no ensino fundamental e até mesmo no médio,

Detém poucas informações sobre os exames vestibulares e a formação universitária. Muitas vezes não há conhecimento sobre quais Instituições de Ensino Superior existem na região, no estado, que cursos são oferecidos e como ocorre a seleção dos candidatos. Ao adquirirem tais informações, seja de forma fragmentada ou em sua totalidade, emerge a questão do desânimo em prestar o vestibular, dada as condições de sua formação escolar. Existem, também, estudantes que desejam a formação acadêmica, visando aumentar as chances de melhores postos no mercado de trabalho. Porém, a escolha do curso recaí sobre os menos concorridos, onde, provavelmente, terão mais chances de aprovação.

A situação anterior remete-nos à tese de Bourdieu e Champagne (2003), ao ponderar que cada pessoa faria um investimento segundo sua herança cultural, isto é, o habitus familiar e de sua realidade social. Alguns, ricos em capital cultural tenderiam a investir na educação, entendendo-a como única forma de progressão social, econômica e cultural. Enquanto outros, mais vulneráveis socialmente, por assim dizer, provavelmente optariam por economizar o que ganha, fazer aplicação em uma poupança, no intuito de ter uma reserva para utilizar em um momento de doença, caso ocorra. Ou até mesmo para o funeral de alguém da família. Cada um investiria naquilo que vê que é possível alcançar, mais imediato ou tendo ambições maiores, em grandes feitos.

Os indivíduos iriam aprendendo desde cedo, na prática, que determinadas estratégias ou objetivos são possíveis ou mesmo desejáveis para alguém 
com sua posição social e que outros são inalcançáveis. Esse conhecimento prático iria, aos poucos, se incorporando e se transformando em disposições para a ação. (NOGUEIRA; NOGUEIRA, 2009, p. 45).

Para estes estudantes com menor capital cultural e menos recursos econômicos, conseguir ingressar no Ensino Superior é como se fosse uma "vitória". Logo, a permanência e finalização do curso, constitui outra "vitória". O custeio com os estudos advém de pequenas ajudas da família. E como residem em cidades distantes da terra natal, as despesas são maiores e as estratégias de manutenção no curso são variadas, concomitante a isso, Zago (2006), afirma que:

Nesses casos, residem na casa do estudante universitário (quando há vaga), ou com parente, ou ainda, dividem casa ou apartamento com colegas. Com um 'pé-de-meia' para os primeiros tempos na universidade, os jovens dão início a seus estudos de nível superior sem ter certeza de até quando poderão manter sua condição de universitários. Para viabilizá-la, tentam obter uma renda mediante alguma forma de trabalho em tempo completo ou parcial. (ZAGO, 2006, p. 233).

Algumas questões relacionadas ao trabalho, a exemplo da carga horária, a afinidade ou não com o curso, o resultado financeiro, dentre outras questões. Muitos estudantes conseguem um trabalho que diverge totalmente da sua área de formação e depositam o dia inteiro, isto é, quarenta horas semanais, em tal atividade. Isso afeta no tempo dos estudos, posto que restam poucas horas para tanto. Alguns estudantes conseguem um ofício mais flexível, com obrigatoriedade de exercer poucas horas semanais, como os que prestam serviços para a própria universidade, os que fazem estágio remunerado, tem bolsas de iniciação científica, monitoria de extensão ou ensino ou ainda prestam serviços como autônomos (reforço escolar para estudantes do ensino fundamental, balconistas em supermercados, suporte técnico em informática).

A própria escola, ao privilegiar os mais "espertos", os que desde o nascimento tiveram contato com a cultura letrada e não respeitar as diferenças sociais dos estudantes, imprime uma exclusão social e, de maneira subliminar, uma violência simbólica sobre estes. Tal violência é um denominador comum prevalecente para além da escola, uma vez que a cultura de um determinado grupo é considerada como legítima, a única existente. Há quem deseje, por exemplo, impor o modus viventi sulista, em contraposição ao nordestino; existem aqueles que amam o rock ou a MPB e, consequentemente, desprezam o sertanejo, taxando-o, vulgarmente, de "sertanojo". Outros apreciam o cinema, o teatro e menosprezam uma apresentação de Terno de Reis ou de Candomblé. É sabido que:

Cada campo de produção simbólica seria, então, palco de disputas - entre dominantes e pretendentes - relativas aos critérios de classificação e hierarquização dos bens simbólicos produzidos e, indiretamente, das pessoas e instituições que as produzem. Da mesma forma, seria possível dizer que, no conjunto da sociedade, os agentes travam uma luta, mais ou menos explícita, em torno dos critérios de classificação cultural. Certos padrões culturais são considerados superiores e outros inferiores: distinguese entre alta e baixa cultura, entre religiosidade e superstição, entre conhecimento científico e crença popular, entre língua culta e fala popular. Os indivíduos e as instituições que representam as formas dominantes da cultura buscam manter sua posição privilegiada, apresentando seus bens culturais 
como naturalmente ou objetivamente superiores aos demais. (NOGUEIRA; NOGUEIRA, 2009, p. 32-33).

A escola transmite uma cultura que se "apresenta como legítima, objetiva e indiscutível, como 'neutra', portanto, dissimulando seu caráter arbitrário e sua natureza social" (VALLE, 2013, p. 423). Desta forma, as "chances de acessar ao Ensino Superior resultam de uma seleção que, ao longo do percurso escolar, se exerce com um rigor desigual segundo a origem social dos sujeitos" (BOURDIEU; PASSERON, 1985, p.12). Logo, o público de origem social menos favorecida tende a alienar-se no trabalho, na rotina diária cansativa, que não permite estudar e conquistar novos campos de saber, campos culturais. Assim:

A posição social ocupada no campo do trabalho e as exigências de sobrevivência dominam o cotidiano desse grupo de agentes e os remetem a jogadas sociais, em grande parte bastante previsíveis, que dificilmente fomentam estratégias sociais com probabilidades de leva-los a deslocamentos ascensionais mais amplos. (BRANDÃO, 2010, p.233).

É importante destacar que determinados sujeitos conseguem reverter tal situação, superando o analfabetismo e alienação a que foram submetidos seus pais e seu grupo social, não aceitando o que foi imposto a eles. Eles utilizam da força de vontade própria e conseguem, por aprovação em seleções ou concursos, bolsas de estudo, auxílio transporte, empregos. Utilizam também do capital social que possuem. Esse Capital diz respeito ao conjunto de relações sociais estabelecidas por tais sujeitos como amizades, laços de parentesco, contatos profissionais e beneficiam-se das mesmas para conseguir benefícios materiais, como uma bolsa de estudo, empréstimos de livros, uma banca, uma indicação de um emprego. Podem conseguir vantagens simbólicas, a exemplo de status, prestígio por permear círculos sociais dominantes.

Nestes dois casos, os sujeitos se dedicam mais afinco aos estudos. Conseguem acumular mais informações e conhecimentos, seja através da leitura de livros, seja por meio de programas televisivos, jornais, documentários, acesso à internet, leitura de jornais e revistas.

\subsection{Cursos pré-vestibulares populares e comunitários}

Neste contexto, nota-se nos últimos anos, por parte das classes populares, reclamações e lutas em prol de maior oferta de vagas e condições de ingresso na universidade. Entrementes, a partir dos anos 17, do século XX, observa-se que o ensino privado alavancou maior expansão do que o público, sob o pretexto de democratização popular. Na atualidade esta expansão é ainda maior. Para Tobias (1991) os cursinhos pré-vestibulares sociais e/ou populares, tanto por parte estatal, quanto social, nascem com os exames e as lutas por democratização da educação terciária, perante as contradições do sistema educacional, relacionadas a grandes desigualdades referentes ao acesso à Educação Superior, pois existia a necessidade dos candidatos se prepararem. A partir dos anos 1990, estes cursos são fortalecidos justamente com o intuito de contrapor esta realidade educacional excludente. Assim, Dourado, Catani e Oliveira (2004) ponderam que: 
A partir de meados dos anos 90 , tornaram-se crescentes as ações e debates envolvendo a ampliação e a diversificação do sistema, evidenciados pela criação dos cursos seqüenciais e de alternativas ao vestibular aberto pela LDB (Lei n. 9.394/96); pelo novo programa de crédito educativo (FIES); pela pressão exercida por grupos historicamente excluídos do ensino superior mediante movimentos de isenção da taxa de inscrição para o vestibular e da experiência dos cursos pré-vestibulares alternativos -; e ainda pela introdução do sistema de cotas para alunos negros e outros, oriundos de escolas públicas, como nova forma de acesso à educação superior. (DOURADO, CATANI E OLIVEIRA, 2004, p. 101-102).

Diante disso, percebe-se que é comum que muitos jovens façam o vestibular para a mesma área, duas, três ou mais vezes, até conseguir a aprovação. Alguns entendem que a primeira vez é um "teste", um treinamento para se familiarizar com o processo (ZAGO, 2006). Depois entram em um curso pré-vestibular popular gratuito para irem apreendendo aquilo que sua formação escolar básica não deu conta.

Estes cursos, por sua vez, são diferenciados. Enquanto uns têm sua clientela formada só por estudantes advindos de escolas públicas, outros (privados) têm um público selecionado, que já tem, geralmente, suas carreiras escolhidas a priori. "A origem social exerce forte influência no acesso às carreiras mais prestigiosas, pois a ela estão associados os antecedentes escolares e outros tickets de entrada" (ZAGO, 2006, p. 232).

Os Cursos Pré-Vestibulares Comunitários (CPVCs) são requeridos tanto para dar conta de uma educação básica, quanto tem visão propedêutica, com vistas ao Ensino Superior. Os CPVCs são considerados:

[...] alternativa político-pedagógica conjuntural, enquanto as sociedades política e civil vão estruturalmente desenvolvendo estratégias e medidas adequadas para a conquista - ao longo de uma geração escolar agora iniciando a Educação Infantil - de uma efetiva democratização educacional qualitativa e quantitativa, em que as origens socioeconômicas de baixa renda, as características étnicas, as trajetórias escolares em sucateados estabelecimentos de ensino oficial, o não devido reconhecimento ao multiculturalismo e à diversidade cultural sejam efetivamente superados como barreiras de exclusão escolar. (CARVALHO; ALVIM FILHO; COSTA, 2008, p. 13-14).

Carvalho, Alvim Filho e Costa (2008) citam que a concepção atribuída aos CPVCs de meros espaços pedagógicos deve ser superada, uma vez que, tem se consolidado como expressivos movimentos sociais de caráter urbano e tem adquirido respaldo da sociedade política brasileira. No ano de 1988, a Campanha da Fraternidade, discutiu a questão educacional da juventude negra, o que foi efetivado em 1993, com o Pré-Vestibulares para Negros e Carentes (PVNCs). Antes de 1994, na Bahia, o Grupo Stive Biko inaugurou a experiência de um pré-vestibular para negros. Adiante é criado o Núcleo de Consciência Negra, na Universidade de São Paulo (USP), em 1996. Desde esses primórdios, "os embriões dos CPVCs afirmam-se crescentemente como um movimento social de cidadania ativa, inclusão social e resgate de uma dívida que o Brasil tem, historicamente, com a sua população afrodescendente" (CARVALHO, ALVIM FILHO e COSTA, 2008, p. 24). Existe a proposta que almeja nivelar ou aproximar ao máximo as oportunidades do estudante de baixa renda com as daquele que 
recebeu formação em uma escola média de melhor nível e que tem condições financeiras para pagar um cursinho comercial (BACCHETTO, 2003).

A organização dos CPVCs, de maneira geral, dá-se em locais pobres, capitaneados por igrejas, movimentos sociais e escolas de classe média que detém engajamento social. Os envolvidos almejam a afirmação identitária, o posicionamento social, político, a mudança de determinada realidade, a democratização do acesso à educação terciária. Assim, é plausível considerar como vitória dos CPVS, no viés político, a criação do Programa Universidade para Todos (POUNI) pelo Congresso Nacional, a maior oferta de vagas públicas no ensino superior, nos últimos anos, a possibilidade de uso do ENEM para aquisição de financiamentos educativos, a seleção do ensino superior por meio dos resultados do Exame Nacional do Ensino Médio (ENEM).

No que tange ao corpo docente (ou monitores) e coordenadores destes cursos, costumeiramente, tem forte engajamento político-social, o que nem sempre denota uma preparação técnica à altura. Atuam, na maioria, de forma voluntária. A maior parte está se graduando ainda em processo de formação em "cursos de licenciatura e bacharelado, com variadas faixas etárias e diversos períodos de engajamento nos CPVCs, e que comungam um compromisso social e comunitário". (CARVALHO, ALVIM FILHO e COSTA, 2008, p. 28). Determinada parte dos docentes (ou monitores) é leiga, não possuem muita disponibilidade de tempo já que trabalham em outros locais e estudam e não concluíram a graduação, não tendo muitas habilidades pedagógicas para a atividade docente. Infelizmente, em muitos casos, os cursos não possuem recursos materiais adequados para o melhor desenvolvimento das aulas.

Como afirma Bacchetto (2003), Mitrulis e Penin (2006), os PVC's, além de funcionar como forma de empoderamento e fortalecimento de identidade daqueles que os constituem, são uma das formas de se pressionar as autoridades governamentais para serem executadas políticas públicas democráticas visando o acesso e permanência de grupos menos favorecidos ao Ensino Superior público. Isso mostra que, apesar da precariedade, os PVC's podem se constituir em iniciativas de politização do debate sobre o referido nível de educação no país. Cabe então questionar se esses estariam expressando essas iniciativas, se tais se constituem, além do atendimento à uma demanda imediata, em um espaço de articulação para a defesa das demandas desses jovens, quanto esses cursos colaboram para uma mudança de pensamento na constituição das motivações e expectativas de seu público, e até que ponto os processos educativos dessas iniciativas influenciariam em um contexto mais global.

\subsection{Curso pré-vestibular Universidade Para Todos}

Este programa foi criado por meio do Decreto № 8.583, de 14 de julho de 2003, integrante de um programa mais amplo cujo nome é Faz Universitário e este faz parte do Programa de Educação Tributária da Bahia (PET/BA). A Secretaria da Fazenda e a Secretaria de Educação da Bahia gerenciam todas as atividades. O decreto citado foi alterado pelo Decreto oㅜ 9.149, de 23 de julho de 2004. Dentre os objetivos do programa está: fornecer condições de igualdade no mercado de trabalho para alunos egressos da Rede Pública, mediante o aprofundamento de estudos com vistas à realização dos processos seletivos de ingresso em Instituições de Ensino Superior (IES), conceder bolsas de estudos 
ou bolsas-auxílio para cursar o nível superior, proporcionar bolsa de iniciação ao trabalho, conscientizar sobre importância do imposto para o fomento da cidadania.

Art. $1^{\circ}[\ldots]$ o Faz Universitário visa promover condições de igualdade social no mercado de trabalho para alunos egressos da Rede Pública de Ensino Estadual e/ou Municipal do Estado da Bahia sendo coordenado pela Secretaria da Fazenda e desenvolvido em parceria com a Secretaria da Educação do Estado da Bahia, com os seguintes objetivos:

I - aprofundar os conhecimentos da Educação Básica, adquiridos pelos alunos da Rede Pública de Ensino, visando ao processo seletivo em Instituições de Ensino Superior - IES;

II - subsidiar, mediante Bolsas de Estudo, formação de nível superior para alunos egressos da Rede Pública de Ensino Estadual e/ou Municipal do Estado da Bahia, que vierem a ingressar em IES particulares do Estado;

III - subsidiar, mediante Bolsa-Auxílio, formação de nível superior de alunos egressos da Rede Pública de Ensino Estadual e/ou Municipal do Estado da Bahia aprovados em processo seletivo em IES públicas no Estado da Bahia; IV propiciar experiência profissional mediante Bolsa Iniciação ao Trabalho, a alunos egressos da Rede Pública de Ensino Estadual e/ou Municipal do Estado da Bahia que cursam em IES públicas no Estado da Bahia;

$V$ - estimular a compreensão da função social do imposto;

VI - incentivar o exercício da cidadania. (BAHIA, 2004).

Perante estes pressupostos, o Projeto Faz Universitário se divide em duas fases: I- Preparando para a Universidade e II- Cursando a Universidade. Na primeira objetiva-se fornecer condições, por meio de capacitação, para que os alunos egressos das escolas públicas da Bahia, obtenham êxito nos processos seletivos, mediante as seguintes condições:

Art. 4으. I- Universidade para Todos: curso preparatório, com aulas presenciais e/ou à distância, visando ao ingresso de alunos nas IES, incluindo temas relacionados com a formação da cidadania.

II- Tele Aula consiste em aulas apresentadas em blocos, produzidas em estúdio e veiculadas pela televisão.

Art. 5ำ - Para a ação Universidade para Todos o público alvo será constituído por estudantes egressos da Rede Pública de Ensino Estadual e/ou Municipal do Estado da Bahia.

Art. 6ㅇ - Para a Tele Aula, o público alvo será integrado por estudantes baianos. (BAHIA, 2004).

O Decreto rege, nos artigos sétimo e oitavo, que as aulas do curso preparatório Universidade para Todos deve ter frequência diária, ou seja, de segunda a sexta-feira, com duração de 4 (quatro) horas aulas durante 6 (seis) meses por ano. E no caso da Tele Aula, a periodicidade será semanal, com duração de 1 (uma) hora, no período de março a dezembro. A estrutura organizacional do UPT é coordenada pela Secretaria da Educação (SEC), com execução das ações pelas universidades estaduais, isto é, Universidade do Estado da Bahia (UNEB), Universidade Estadual de Feira de Santana (UEFS), Universidade Estadual do Sudoeste da Bahia (UESB), Universidade Estadual de Santa Cruz (UESC), em vários municípios do estado. É composto de aulas que abrangem 10 (dez) disciplinas, as quais devem ser ministradas, preferencialmente, por professor-monitor a estudantes advindos de escolas públicas. A seleção de alunos e professores ocorre por meio de editais específicos, o que 
geralmente é realizado pela SEC e as universidades. Há também orientação vocacional destinada aos alunos envolvidos. O Artigo 9ำ explica que:

I - As aulas presenciais e à distância abrangerão 10 (dez) disciplinas;

II - Farão parte do conteúdo programático: orientação vocacional, educação fiscal, cidadania e avaliação de conhecimento;

III - As aulas presenciais serão ministradas, preferencialmente, por professormonitor, selecionado entre os alunos graduandos das IES públicas estaduais, mediante edital;

IV - A seleção dos alunos-cursistas obedecerá aos seguintes requisitos:

a) Ter cursado da $5^{\text {a }}$ série do Ensino Fundamental ao 3ํano do Ensino Médio na Rede Pública de Ensino Estadual e/ou Municipal do Estado da Bahia;

b) Ser selecionado através de processo de avaliação a ser definido em edital específico.

V - Serão publicadas em editais específicos todas as informações referentes à inscrição, seleção e matrícula para aluno-cursista, bem como do professormonitor que irá ministrar as aulas.

É importante mencionar que os interessados em realizar o curso UPT precisam atender a critérios determinados em edital específico, publicado, anualmente, no Diário Oficial do Estado (DOE), pela Secretaria de Educação do Estado da Bahia (SEC). Os editais costumam ser muito semelhantes e estipulam a necessidade de realizar a inscrição online. Os interessados devem atender a determinados critérios, como terem cursado o Ensino Fundamental II e Ensino Médio em escola pública sejam concluintes ou egressos do Ensino Médio, além de não estar cursando ou ter concluído o curso

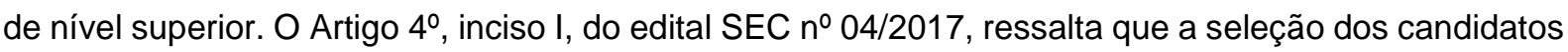
inscritos para efetuar a matrícula no curso deve observar:

[...] opção formulada pelo candidato no requerimento de inscrição, quanto ao Município, local de funcionamento e turno que deseja cursar, e o aproveitamento escolar resultante do cálculo das médias finais obtidas nas disciplinas de Língua Portuguesa e Matemática, transcritas pelo candidato no ato da inscrição. (SEC BAHIA, 2017)

Os candidatos são classificados em ordem decrescente de pontuação e, nas situações que ocorrerem empate na média final das notas obtidas, o desempate será feito dando preferência, sucessivamente ao candidato que possuir: "maior média de Língua Portuguesa e maior idade, considerando-se dia, mês e ano". (SEC BAHIA, 2017). Os estudantes do curso recebem gratuitamente material didático, a exemplo de quatro volumes do módulo elaborado especificamente para o curso, recebem também uniformes e, caso tenham frequentado pelo mesmo $75 \%$ das aulas, fazem jus à isenção da taxa de inscrição em processo seletivo das universidades estaduais. No caso de Aracatu, conforme consulta aos editais da SEC, o curso UPT foi implementado em 2012, com duas turmas e cada uma com 50 alunos. A partir de 2016, o governo estadual, com a política de contenção de gastos, reduz uma das turmas do curso UPT, permanecendo apenas uma.

\section{Metodologia}

A pesquisa consiste em extrair informações, analisar e questionar para que se produzam ideias a partir de dados verídicos e se torne um trabalho científico consistente, respeitada no meio acadêmico 
e garanta a troca de conhecimentos. Muitas vezes é necessário lançar mão de várias estratégias para se fundamentar e desenvolver uma pesquisa e por esta máxima é que se faz opção por realizar este trabalho na perspectiva da Investigação Qualitativa (BOGDAN; BIKLEN, 1994). É relevante destacar que, no primeiro momento, segundo Gil (2002), de acordo com os objetivos, a pesquisa aqui proposta é considerada exploratória, pois...

[...] tem como objetivo proporcionar maior familiaridade com o problema, com vistas a torná-lo mais explícito ou a constituir hipóteses. Pode-se dizer que estas pesquisas têm como objetivo principal o aprimoramento de ideias ou a descoberta de intuições. Seu planejamento é, portanto, bastante flexível, de modo que possibilite a consideração dos mais variados aspectos relativos ao fato estudado. [...]. (GIL, 2002, p.41)

Ocorre, então, a descrição do objeto por meio da pesquisa bibliográfica, a qual, segundo Barros e Lehfeld (2012, p. 34), "é de grande valia e eficácia ao pesquisador porque ela permite obter conhecimentos já catalogados em bibliotecas, editoras, internet”. É necessário o estudo de livros, revistas, jornais, teses, dissertações, anais de eventos científicos e artigos publicados nos periódicos da área. Desta forma é possível identificar, localizar e reunir sistematicamente os materiais e/ou fatos. Com este material bibliográfico e documental, em mãos, avança-se na leitura e conseguinte escrita acerca do tema em evidência, no que tange à fundamentação, ao percurso histórico e à legislação.

No trabalho de campo, para coletar os dados, houve a realização de 25 (vinte e cinco) entrevistas, com alunos que cursaram o curso pré-vestibular Universidade Para Todos (UPT), em Aracatu-BA, nos anos de 2013 e 2014. Neste sentido, através de uma conversa amigável com o "entrevistado, busca levantar dados que possam ser utilizados em análise quantitativa e qualitativa, selecionando-se os aspectos mais relevantes de um problema de pesquisa." (Barros; Lehfeld, 2012, p. 81). É possível explorar os dados verbalizados no que tange aos modelos culturais que se "manifestam na vivência dos indivíduos envolvidos na situação estudada." (Barros; Lehfeld, 2012, p. 82). Desta forma, "os investigadores introduzem-se e despendem [...] tempo [...] tentando elucidar questões educativas". (BOGDAN; BIKLEN, 1994, p. 47). Neste âmbito utiliza-se de notas de campo (BOGDAN; BIKLEN, 1994) para descrever os dados coletados, atentando-se para não separar as falas e/ou os gestos do seu contexto social, para não que o significado não seja perdido. As notas de campo se justificam, justamente, pelo fato de que análise dos dados não é algo que se dá exclusivamente a posteriori da realização das entrevistas.

A análise, neste sentido, já começa desde o processo de inteligibilidade estabelecido pelo pesquisador em todos os momentos, inclusive durante a própria entrevista. "A palavra escrita assume particular importância na abordagem qualitativa, tanto para o registro dos dados como para a disseminação dos resultados." (BOGDAN; BIKLEN, 1994, p. 49). Assim, nada é trivial, tudo tem potencial para auxiliar na compreensão do objeto. A análise dos dados, nesta perspectiva, tende ao caráter indutivo. Os dados recolhidos não objetivam reforçar ou desconstruir hipóteses préestabelecidas, uma vez que as categorias são elaboradas a partir da captação dos dados. "O processo de análise dos dados é como um funil: as coisas estão abertas de início (ou no topo) e vão se tornando 
mais fechadas e específicas no extremo". (BOGDAN; BIKLEN, 1994, p. 50). Ocorre uma seleção das coisas/informações mais importantes.

\section{Resultados e discussão}

Vale ressaltar que o estudo aqui apresentado foi desenvolvido pautado no Conselho Nacional de Ética em Pesquisa. O Termo de Consentimento Livre e Esclarecido foi assinado por todos entrevistados para que todos os envolvidos com a pesquisa estejam cientes do sério trabalho desenvolvido, de acordo com os princípios éticos da profissão para que nenhum seja prejudicado e tenha a integridade mantida tanto de quem pesquisa como também daquilo ou de quem é pesquisado. Foram, então, realizadas 25 (vinte e cinco) entrevistas, contendo 11 (onze) questões, com alunos que estudaram no curso pré-vestibular Universidade Para Todos (UPT), nos anos de 2013 e 2014. Destes, houve a seleção de 10 (dez) entrevistados, entre os quais 5 (cinco) são do sexo masculino e 5 (cinco) do sexo feminino, com idades oscilando entre os 17 e 32 anos. A maioria, isto é, 7 (sete) reside na zona urbana, no bairro centro e nos bairros periféricos e os demais, 3 (três), na zona rural.

Todos os entrevistados estudaram os ensinos fundamental e médio em escolas públicas, fazem parte de famílias de classe social baixa ou média, cujos pais são trabalhadores urbanos, prestam serviços para a prefeitura, como professores, serviços gerais. Outros pais atuam no comércio local, como balconistas, vendedores, serviços gerais, ou pedreiros, serventes de pedreiros, faxineiras. No caso dos pais de estudantes da zona rural, como é de praxe, trabalham como lavradores. Alguns recebem um salário mínimo, outros recebem valores inferiores a isso e há aqueles que tem a maior parte da renda advinda de programas sociais, do governo federal, como o Bolsa Família.

Das 11 (onze) questões postas, houve a seleção de 5 (cinco) para melhor explanar a proposta deste trabalho. A primeira questão refere-se à primeira e segunda opções de curso desejado (s) a fim de realizar vestibular e as respostas mais comuns, são observadas no quadro abaixo.

Quadro 1 - Escolha dos cursos para realizar o vestibular

\begin{tabular}{|l|c|c|}
\hline Curso & Quantidade de respostas & Percentual \% \\
\hline Enfermagem & 4 & $20 \%$ \\
\hline Direito & 3 & $15 \%$ \\
\hline Educação Física & 3 & $15 \%$ \\
\hline Psicologia & 2 & $10 \%$ \\
\hline História & 2 & $10 \%$ \\
\hline Ciências Biológicas & 2 & $10 \%$ \\
\hline Medicina & 1 & $5 \%$ \\
\hline Administração & 1 & $5 \%$ \\
\hline Técnico em Edificações & 1 & $5 \%$ \\
\hline Letras & 1 & $5 \%$ \\
\hline
\end{tabular}

Fonte: Os Autores (2017) 
Diante do quadro 1 (um), é possível determinar as seguintes categorias: a) cursos de licenciaturas, isto é, Educação Física, História, Ciências Biológicas e Letras, atingem 40\% da preferência do público entrevistado; b) no tocante aos cursos na área da saúde: Medicina e Enfermagem somam 25\% das opções; c) O curso de Direito, que costuma, ser muito bem ranqueado, apresentou apenas 15\% das escolhas; d) Já Psicologia pontuou 10\%, da preferência; e) Administração teve 5\% da preferência; f) E o curso Técnico em Edificações alcançou a mesma pontuação do curso anterior, isto é, $5 \%$. A segunda questão escolhida para análise diz respeito aos motivos que levaram à escolha de determinado (s) curso (s). A prerrogativa da distância geográfica foi descrita pela maioria dos entrevistados, ou seja, 6 (seis). Pois, segundo eles, seria mais fácil e viável escolher um curso que existisse em uma universidade ou faculdade mais próxima da residência, haja vista que nem eles e nem os pais teriam condições financeiras para pagar os gastos em cidades distantes ou em outros estados. Foi ressaltada também, em algumas respostas, a afinidade vocacional pelo curso. No tocante ao terceiro quesito, isto é, qual a avaliação do curso UPT e se superou as expectativas, as repostas são variadas, a saber: - "avalio como boas, embora precisam ser melhoradas"; - "avalio como bom curso, pois me auxiliou bastante nos vestibulares realizados"; - "ótimo curso, excelente com certeza. Supriu as expectativas de ensino e aprendizagem. O grau de aprendizado foi ótimo, uma vez que fiquei nove anos sem estudar e aprendi bastante coisas com o cursinho. Vou sentir saudades". Algumas ponderações críticas podem ser destacadas como: - "poderia melhorar alguns professores do curso"; - "sobre as aulas não tenho muito que dizer, só que em algumas disciplinas o professor demorava no mesmo assunto. Não superou as expectativas completamente, talvez por não sentir gosto de algumas aulas dadas. E não tive muito interesse".

A quarta questão é objetiva e pretende saber se os estudantes consideram o curso excelente, bom, regular, ruim ou péssimo. Então, as respostas foram as seguintes: 4 (quatro) estudantes assinalaram como excelente, 5 (cinco) marcaram a opção bom e 1 (um) marcou como regular. Posteriormente, os estudantes foram indagados, no quesito 5 (cinco), sobre os aspectos relevantes tanto no viés positivo, como no negativo. Assim, destaca: - "é preciso uma estratégia para cativar os alunos a não desistirem do curso"; - "os módulos chegaram atrasados e isso foi ruim; - "o curso foi muito bom. Tive uma frequência razoável, por motivos de transporte que apresentava defeito"; - "Só acho que o curso deveria começar mais cedo e a coordenação tomar providências com os alunos que perturbam as aulas".

\section{Considerações finais}

Destaca-se que o maior investimento na educação universitária é visto como uma alavanca para de progressão da economia, uma forma dos indivíduos conseguirem melhores postos de trabalho e terem melhores rendas. A Organização para a Cooperação e Desenvolvimento Econômico (OCDE), organizou um relatório denominado Olhar sobre a Educação, em 2009, o qual propõe mais investimentos na educação superior, contribuindo para elevar a competência da população e da mão de obra, além de corroborar para o desenvolvimento do capitalismo. Maués (2010) ao fazer referência ao supracitado relatório da OCDE pondera que a educação superior: 
aparece como sendo a senha para o emprego e para maiores salários. [...] As pessoas do sexo masculino, titulares de diploma de nível superior, gozam de uma vantagem salarial, que no caso, do Brasil, por exemplo, chega a $100 \%$ em relação às pessoas que têm apenas o nível médio. Já as mulheres refletindo a diferença de renda entre os gêneros, tem uma diferença menor. (OCDE, 2009, p. 148 apud MAUÉS, 2010, p. 3).

Acrescenta-se que a Conferência Mundial sobre a Educação Superior, realizada em julho de 2009 na sede da Unesco, em Paris pontua a cerca da mudança social e do desenvolvimento a partir da educação superior, pré-requisito fundamental para que se postule uma sociedade igualitária, nutrida pela integração social, digital e composta por sujeitos criativos, fomentado o bem-estar social dos povos do mundo. No que tange aos cursos pré-vestibulares populares e comunitários implica-se toda uma discussão do percurso escolar dos estudantes das classes sociais menos favorecidas. Conforme já há muito tempo explicitado por Bourdieu (1985), cada um dará a importância e fará o investimento que considera viável, de acordo sua experiência e sua expectativa ora de ascensão social, ora de manutenção do status quo, ora de empregabilidade. Neste contexto, tais cursos, conforme os relatos dos sujeitos entrevistados, podem colaborar, no âmbito do preparo dos conteúdos essenciais para os processos seletivos, elevando os níveis de conhecimentos dos estudantes, podem contribuir na elevação da autoestima e de apresentar possibilidades de lograr êxito no acesso aos estudos acadêmicos.

Claro que não basta que o estudante esteja em um curso preparatório gratuito para o vestibular, como é o caso, em evidência, do Universidade para Todos, implementado em Aracatu/BA, em 2012, e também que a equipe técnica/pedagógica seja capacitada em suas respectivas áreas de atuação. Evidencia-se que o empenho dos profissionais, sob o prisma de acreditar que o aluno é capaz, promover sua autoestima e trabalhar os conteúdos, resoluções de questões de vestibular e simulado, à altura das exigências de um processo seletivo. Pois os cursos não devem existir apenas como paliativos sociais, mas como fortes e consolidadas políticas públicas que assegurem (ou almejem assegurar) condições iguais (ou semelhantes) àquelas dos cursos da iniciativa privada.

O Brasil precisa avançar muito no que diz respeito às condições de poder dar conta de oferecer a preparação eficiente para a educação em nível superior para um contingente maior de sua população. Assim torna-se imprescindível, também a ampliação do número de instituições públicas, de forma estruturada e mediante as condições sociais e econômicas de cada público atingido. Os problemas relacionados à seleção no nível superior e a permanência no mesmo, advém primeiramente, não só do ambiente universitário, mas sim dos mecanismos sociais, que, historicamente, são excludentes, frutos de uma sociedade historicamente hierárquica e profundamente desigual. Desta forma, "a esperança de inclusão dos enormes contingentes que buscarão educação superior nos próximos anos [...] passa pelas políticas de fortalecimento do setor público." (PACHECO; RISTOFF, 2004, p. 9).

Com isso, acredita-se que é possível que os estudantes de classe social menos favorecida, pelo menor acesso aos bens culturais, pelo menor acúmulo de capital econômico, quebrem o paradigma posto, do fracasso escolar a acadêmico. E assim alcancem os objetivos que tanto vislumbram. 


\section{Referências}

BACCHETTO, João Galvão. Cursinhos pré-vestibulares alternativos no Município de São Paulo (1991-2000): a luta pela igualdade no acesso ao ensino superior. São Paulo, 2003. Tese. Feusp. <Disponível em: http://www.teses.usp.br/teses/disponiveis/48/48134/tde-07082003-114804/ptbr.php. ... Acesso em: 10 abr. 2017.

BAHIA. Decreto no 8.080, de 11 de dezembro de 2001. Regulamenta os incisos que passa a ser denominado Programa Estadual de Incentivo à Formação Universitária: (...). Disponível em: https://governo-ba.jusbrasil.com.br/legislacao/78285/decreto-8080-01>. Acesso em: 30 jan. 2016.

BAHIA. Decreto no 8.583, de 14 de julho de 2003. Aprova o Regulamento do Programa Faz Universitário vinculado ao Programa de Educação Tributária do Estado da Bahia e dá outras providências. Diário Oficial do Estado da Bahia (DOE), Salvador, BA, 14 de jul. de 2003. Disponível em: https://governo-ba.jusbrasil.com.br/legislacao/77500/decreto-8583-03?print=true $>$. Acesso em: 30 jan. 2016.

BAHIA. Decreto no 9.149, de 23 de julho de 2004. Aprova o novo Regulamento do Programa Faz Universitário vinculado ao Programa de Educação Tributária do Estado da Bahia, e dá outras providências. Diário Oficial do Estado, Salvador, BA, 24 de jul. 2004. Disponível em: http://www.sec.ba.gov.br/uptsys/arquivos/decreto 9149 de 23 de julho de 2004 faz universitario e upt.pdf >. Acesso em: 10 marc. 2015.

BARROS, Aidil de Jesus Paes de; LEHFELD, Neide Aparecida de Souza. Projeto de pesquisa: propostas metodológicas. 21. Ed. - Petrópolis, RJ: Vozes, 2012.

BOGDAN, Robert C.; BIKLEN, Sari Knopp. Investigação qualitativa em educação. Porto Editora, LDA, 1994. Porto: Portugal.

BRASIL. Decreto no 8.659, de 5 de Abril de 1911. Aprova a Lei Orgânica do Ensino Superior e do Fundamental na República. Diário Oficial da União, Brasília, DF, 5 de abr. 1911. Disponível em: http://www2.camara.leg.br/legin/fed/decret/1910-1919/decreto-8659-5-abril-1911-517247-

publicacaooriginal-1-pe.html>. Acesso em: 30 abr. 2017.

BOURDIEU, Pierre; CHAMPAGNE, Patrick. Os excluídos do interior. In: NOGUEIRA, Maria Alice; CATANI, Afrânio Mendes. (Org.). Escritos de educação. Petrópolis: Vozes, 2003.

BOURDIEU, Pierre; PASSERON, Jean-Claude. A reprodução: elementos para uma teoria do sistema de ensino. 2.ed. Rio de Janeiro: Francisco Alves, 1985.

BRANDÃO, Zaia. Operando com conceitos: com e para além de Pierre Bourdieu. Educação e Pesquisa, São Paulo: 2010. Disponível em http://www.scielo.br/pdf/ep/v36n1/a03v36n1.pdf>. Acesso em 08 nov.2014.

CARVALHO, José Carmelo Braz de; ALVIM FILHO, Hélcio; COSTA, Renato Pontes. Cursos prévestibulares comunitários: espaços de mediações pedagógicas. Rio de Janeiro: Ed. PUC-Rio, 2008. DOURADO, Luiz Fernandes; CATANI, Afrânio Mendes; OLIVEIRA, João Ferreira de. Políticas públicas e reforma da educação superior no Brasil: impasses e perspectivas. Pro-Posições, Campinas, SP, v.15, n. 3, p. 91-115, 2004.

GIL, Antônio Carlos. Como elaborar projetos de pesquisa. 4. ed.12. reimpr. São Paulo: Atlas, 2002. 
MAUÉS, Olgaises Cabral. Educação Superior e o Trabalho Docente no Contexto da Crise do

Capital. Disponível em: http://www.anpae.org.br/iberolusobrasileiro2010/cdrom/95.pdf. Acesso em 10 jan. 2017.

MITRULIS, Eleny; PENIN, Sônia Teresinha de Sousa. Pré- vestibulares alternativos: da igualdade à equidade. Cadernos de Pesquisa, v.36, n 128, p.269-298, maio/ ago.2006.

NOGUEIRA, Maria Alice; NOGUEIRA, Cláudio M. Martins Nogueira e. Bourdieu e a Educação. 3. Ed. Belo Horizonte: Autêntica, 2009.

PACHECO, Eliezer; RISTOFF, Dilvo Ilvo. Educação superior: democratizando o acesso. Brasília: Instituto Nacional de Estudos e Pesquisas Educacionais. 2004. (Série Documental: Textos para Discussão, 12).

PAIM, Antônio. Por uma universidade no Rio de Janeiro. In: SCHARTZMAN, Simon (org) e outros. Universidades e instituições científicas no Brasil. Brasília: CNPq, 1982.

SANTOS, Janete dos. Política pública de acesso ao ensino superior: um olhar sobre a utilização do EBEM/SISU na Universidade Federal do Recôncavo da Bahia. Disponível em: http://www.xiconlab.eventos.dype.com.br/resources/anais/3/1308337559 ARQUIVO Artigoconlab1.p df. >. Acesso em 05 jun.2015.

SEC BAHIA. Edital № 004/2017, de 25 de maio de 2017. Processo seletivo para o curso preparatório Universidade Para Todos. Disponível em: $<$ http://www.sec.ba.gov.br/uptsys/arquivos/edital \%20de inscricao upt 2017.pdf.>. Acesso em: 28 jun. 2018.

TOBIAS, José Antonio. História da educação brasileira. 4 ed. São Paulo: IBRASA, 1991.

VALLE, Ione Ribeiro. O lugar da educação (escolar) na sociologia de Pierre Bourdieu. Curitiba: Diálogo Educativo, 2013.2 Disponível em: http://www2.pucpr.br/reol/index.php/dialogo?dd1=7629\&dd99=view.. . Acesso em 20 nov.2015.

ZAGO, Nadir. Do acesso à permanência no ensino superior: percurso de estudantes universitários de camadas populares. Revista Brasileira de Educação, v. 11 n. 32 maio/ago. 2006. 